\title{
MAKETING VERDE E COMPRA DOS CONSUMIDORES: ESTUDO DE CASO MÚLTIPLO EM SUPERMERCADOS ${ }^{1}$
}

\author{
GREEN MARKETING AND CONSUMER BUYING: \\ MULTIPLE CASE STUDY IN SUPERMARKETS
}

\section{MAKETING VERDE Y COMPRA DE LOS CONSUMIDORES: ESTUDIO DE CASO MÚLTIPLE EN SUPERMERCADOS}

\begin{abstract}
Antonia Cláudia dos Santos Costa, Bacharel em Administração pela Universidade Federal do Piauí-Campus Parnaíba. Universidade Federal do Piauí (UFPI), Campus Ministro Reis Velloso. Av. São Sebastião, 2819 - São Benedito, Parnaíba - PI, CEP 64202-020. Telefone: (086) 3323-5314. E-mail: claudiascosta@ outlook.com.
\end{abstract}

Henrique César Melo Ribeiro, Doutor em Administração pela Universidade Nove de Julho (Uninove-SP). Endereço Profissional: Universidade Federal do Piauí (UFPI), Campus Ministro Reis Velloso. Av. São Sebastião, 2819 - São Benedito, Parnaíba - PI, CEP $64202-$ 020. Telefone: (086) 3323-5314. E-mail: hcmribeiro@gmail.com.

Antônia Amanda Alves Pereira Moreira, Bacharel em Administração pela Universidade Federal do Piauí-Campus Parnaíba. Universidade Federal do Piauí (UFPI), Campus Ministro Reis Velloso. Av. São Sebastião, 2819 - São Benedito, Parnaíba - PI, CEP 64202-020.

Telefone: (086) 3323-5314. E-mail: amanda_alves-96@hotmail.com.

\section{RESUMO}

É notável a crescente preocupação da sociedade e de grandes grupos organizacionais de um modo geral, com as questões ambientais. A abordagem sustentável é urgente e precisa ser vista com mais atenção. Diante disso, o marketing torna-se uma medida de extrema importância no auxilio do processo empresarial no que se refere às praticas sustentáveis, desenvolvendo um perfil estudado a respeito do mercado consumidor, como clientes, concorrentes e fornecedores através do marketing verde. O objetivo geral desse estudo é compreender o envolvimento do marketing verde na escolha de compra dos consumidores em supermercados. A metodologia adotada é de abordagem qualitativa com procedimento metodológico voltado para um estudo de caso múltiplo. Diante dos dados analisados, percebe-se que as instituições estudadas consideram importante o consumo dos produtos verdes e a divulgação da temática ambiental, mas não praticam essa filosofia visto que mesmo com clientes que se mostram interessados pelas práticas ambientais, as empresas não possuem um planejamento para a satisfação desses clientes e é natural concluir que se as empresas tivessem interesse em implantar a estratégia de marketing verde esse número de pessoas poderia ser bem maior.

Palavras-chave: Sustentabilidade. Marketing. Marketing Verde. Consumidores Verdes.

\section{ABSTRACT}

1 Artigo submetido em 14/08/2018, revisado em 19/02/2019, aceito em 11/03/2019 e divulgado em 30/10/2019 pelo EditorAlexandre Rabêlo Neto, após double blind review.

GєCont, v.6, n. 1, Floriano-PI, Jan-Jun. 2019. 
The growing concern of society and large organizational groups in general with environmental issues is noteworthy. The sustainable approach is urgent and needs to be seen more closely. Given this, marketing becomes an extremely important measure in helping the business process with regard to sustainable practices, developing a profile of the consumer market, such as customers, competitors and suppliers through green marketing. The overall objective of this study is to understand the involvement of green marketing in consumer choice in supermarkets. The methodology adopted is a qualitative approach with a methodological procedure focused on a multiple case study. Considering the analyzed data, it is noticed that the studied institutions consider important the consumption of green products and the dissemination of the environmental theme, but do not practice this philosophy since even with customers who are interested in environmental practices, companies do not have a planning to the satisfaction of these customers and it is natural to conclude that if companies had an interest in implementing the green marketing strategy that number of people could be much higher.

Keywords: Sustainability. Marketing. Green Marketing. Green Consumers.

\section{RESUMEN}

Es notable la creciente preocupación de la sociedad y de grandes grupos organizacionales de un modo general, con las cuestiones ambientales. El enfoque sostenible es urgente y necesita ser visto con más atención. Por lo tanto, el marketing se convierte en una medida de extrema importancia en el auxilio del proceso empresarial en lo que se refiere a las prácticas sostenibles, desarrollando un perfil estudiado respecto al mercado consumidor, como clientes, competidores y proveedores a través del marketing verde. El objetivo general de este estudio es comprender la implicación del marketing verde en la elección de compra de los consumidores en supermercados. La metodología adoptada es de abordaje cualitativo con procedimiento metodológico orientado hacia un estudio de caso múltiple. En los datos analizados, se percibe que las instituciones estudiadas consideran importante el consumo de los productos verdes y la divulgación de la temática ambiental, pero no practican esa filosofía ya que incluso con clientes que se muestran interesados por las prácticas ambientales, las empresas no poseen una planificación para la satisfacción de estos clientes y es natural concluir que si las empresas tuvieran interés en implantar la estrategia de marketing verde ese número de personas podría ser mucho mayor.

Palabras clave: Sostenibilidad. Marketing. Marketing Verde. Consumidores Verdes.

\section{INTRODUÇÃO}

notável a crescente preocupação da sociedade e de grandes grupos
organizacionais de um modo geral, com as questões ambientais. O uso degradação do meio ambiente sem precedentes. Dentre as maiores causas do desequilíbrio ambiental, a industrialização é apontada como a principal, seja pelos usos de matérias primas naturais escassas ou por sua utilização sem planejamento (SCHMITZ, 2014). A abordagem sustentável é urgente e precisa ser vista com mais atenção.

A sustentabilidade pode ser definida como um processo decorrente dos efeitos provocados pelos problemas ambientais que vem assolando o mundo, além de uma preocupação com a evolução do tema no futuro (PRATES et al., 2015). Sustentabilidade pode ser entendida como um processo realizado com a capacidade de se sustentar, de ser autossuficiente. É criado como um mecanismo capaz de respeitar a capacidade de desenvolvimento do ecossistema (MIKHAILOVA, 2004). 
Apenas a partir da década de 1970 é que os conceitos sustentáveis vieram a surgir. Os objetivos presentes até então eram de promover a satisfação da atual geração sem comprometer as gerações futuras, levando em consideração a qualidade de vida resguardando os recursos naturais (CHAVES et al., 2014). E mesmo hoje em dia, apesar do grande avanço que já ocorreu não se pode dizer que houve uma grande reforma, mas sim uma pequena transformação (LAYRARGUES, 2000).

Embora os conceitos de sustentabilidade sejam de certo modo simples de se entender, colocá-los em prática ainda se torna uma dificuldade para muitas empresas (TELES et al.,2016). Reforçando esse conceito, é importante ressaltar que há dificuldades não só em nível empresarial, mas também no sentido de que para que haja um modelo sustentável de um modo geral, é preciso que ocorra um pacto intergeracional, a geração atual proporcionando a renovação dos recursos para as futuras gerações (BARBIERI, 2007).

As empresas já perceberam que precisam se enquadrar nos moldes sustentáveis. Isso ocorre primeiro porque os consumidores estão mais atentos às empresas que mantêm um comportamento ecologicamente correto, e depois "a influência ecológica cresce e os efeitos econômicos aumentam consideravelmente" (CHAVES et al., 2014).

As empresas têm papel importante nessa questão ambiental. E uma das formas de fazer parte efetiva desse processo é obtendo certificações ambientais. Uma das normas que proporcionam às empresas essa integração com a gestão ambiental são as normas de qualidade ISO 14000 International Organization for Standardization (Organização Internacional de Normalização). Esse certificado tem como objetivo minimizar os danos causados ao meio ambiente. As empresas que se encontram em conformidade com as políticas e leis ambientais estão aptas à adoção da ISO 14000.

Devido ao constante crescimento econômico e o espaço no mercado cada vez mais acirrado, as empresas necessitam buscar estratégias para manter a competitividade e seus clientes além de conquistar novos clientes. Além disso, apostar na conscientização das questões ambientais é uma forma de se diferenciar da concorrência (PEREIRA et al.,2014). Diante disso, o marketing torna-se uma medida de extrema importância no auxílio do processo empresarial no que se refere às praticas sustentáveis, desenvolvendo um perfil estudado a respeito do mercado consumidor, como clientes, concorrentes e fornecedores através do marketing verde (VIEIRA et al., 2012).

O Marketing verde é a estratégia de marketing voltada ao processo de venda de produtos e serviços que são baseados nos seus benefícios ao meio ambiente. É a estratégia de vinculação da marca, produto ou serviço a uma imagem ecologicamente consciente e dentro dessa proposta surge como estratégia empresarial que visa trazer uma percepção de responsabilidade ecológica tanto dentro das organizações quanto fora dela. Oferece ao consumidor a oportunidade de desfrutar de produtos sustentáveis, propondo a conscientização desse tipo de produto (PEREIRA et al., 2014).

O marketing verde recebe outras denominações como Marketing Ambiental, Ecologicamente Correto ou Ecomarketing (FÜHR; ALLES, 2000). Ainda conforme o autor, o marketing ambiental é visto sob duas óticas: contribuir para o desenvolvimento ambiental, além de oferecer mais chances de negócios. É importante mencionar ainda o termo green washing, um método utilizado com a proposta de maquiar produtos não sustentáveis com a proposta verde a fim de fazê-los se passar por ecologicamente corretos (CHAVES et al., 2014).

E com o desafio de criar uma conscientização do consumo sustentável, o marketing verde busca elaborar estratégias que levem o consumidor a repensar suas práticas de consumo. Diante de muitas dificuldades que as organizações enfrentam para a implementação da estratégia do marketing verde, uma delas está na desvantagem do preço em relação a produtos não sustentáveis. E, além disso, existe o fato de que uma grande parte da população não está 
sendo instigada a alterar hábitos e modos de agir, seja para não perder seu conforto, seja para se sacrificar de algum modo (ALMENDRA, 2012).

Mediante as informações expostas anteriormente, o presente trabalho tem como questão norteadora: como ocorre o envolvimento do marketing verde na escolha de compra dos consumidores em supermercados? A fim de responder está indagação o estudo tem como objetivo geral compreender o envolvimento do marketing verde na escolha de compra dos consumidores em supermercados. Para tanto foram desenvolvidos os seguintes objetivos específicos: (1) entender a relação existente entre o consumidor e os produtos sustentáveis; (2) averiguar as práticas de compra dos consumidores sob a ótica dos stakeholders; (3) observar o que pensam os stakeholders sobre a estratégia de marketing verde; e (4) evidenciar a importância que o marketing verde traz para as organizações ora estudadas.

A referida pesquisa justifica-se pelo fato de haver uma necessidade urgente de mudança quando o assunto é o desenvolvimento sustentável. As ocorrências sofridas pelo mundo atualmente como mudanças climáticas, escassez de matérias primas, extinção de espécies animais, são resultantes dos hábitos desenvolvidos pela humanidade. Os recursos naturais, por exemplo, utilizados pelas indústrias de maneira exploratória faz com que acabe gerando uma escassez de materiais em longo prazo prejudicando o meio ambiente, pois os produtos resultantes desse processo industrial acabam voltando à natureza e demorando anos para serem degradados.

O consumo atualmente é feito sem nenhum tipo de crítica. A grande parte dos produtos comercializados é resultante de um processo industrial que não pensa nas consequências que os dejetos oriundos da sua fabricação podem provocar no ambiente. É um processo realizado apenas com base no lucro sem nenhuma responsabilidade social, significando, dessa forma que não trazem nenhum benefício social ou ambiental, apenas econômico.

A metodologia adotada é de abordagem qualitativa com procedimento metodológico voltado para um estudo de caso múltiplo. A pesquisa visa contribuir para a pesquisa científica do assunto em questão, servindo assim de base para futuras pesquisas mais aprofundadas sobre a temática e também se busca com a execução desse trabalho aumentar as fontes relativas ao tema de marketing verde, expondo as escolhas tomadas por consumidores além de enfatizar a importância do produto verde para a sustentabilidade ambiental.

E, sobretudo sensibilizar consumidores para essa problemática através da conscientização para o uso de produtos sustentáveis, por meio da aplicação do marketing verde, além de divulgar a importância de se aderir a essa causa, em vista que novos hábitos, novas atitudes acabam trazendo um novo modo de ver o consumo que deve ser feito de maneira consciente e sustentável. A seção seguinte compete ao referencial teórico, posteriormente serão apresentados à metodologia, seguida da análise e discussão dos dados coletados e, por fim, as considerações finais desse estudo.

\section{REFERENCIAL TEÓRICO}

Com a pretensão de aprofundar as informações a cerca do tema, apresenta-se nessa seção os assuntos relacionados no estudo: Sustentabilidade, Marketing, Marketing Verde e Consumidores Verdes.

\subsection{Sustentabilidade}

A sustentabilidade pode ser conceituada como um método que leva a empresa a se desenvolver sem a necessidade de explorar os recursos naturais. E para desenvolver metodologias para continuar seu processo produtivo é necessário planejamento para encontrar 
meios de diminuir a utilização de matérias-primas, aumentando métodos de reutilização e reciclagem de materiais (MATTOS, 2008).

O conceito de desenvolvimento sustentável é de certa forma, novo e que somente nas últimas décadas vem sendo notado. Principalmente depois de eventos como a Eco-92, evento realizado no Rio de Janeiro, e a formulação da Agenda 21. A prática da sustentabilidade tratase de um investimento. São atitudes pensadas e desenvolvidas na atualidade para proporcionar segurança às gerações futuras, no entanto, para isso é necessário que todos se conscientizem de seus deveres perante as causas ambientais (MATTOS, 2008).

Os problemas ambientais que assolam a sociedade muitas vezes são causados por ela mesma. Muitas pessoas não têm consciência do que estão acarretando com hábitos pouco sustentáveis. Os efeitos desse comportamento provocam efeitos destrutivos na natureza como a poluição; diminuição de hábitats e; de substâncias essenciais à sobrevivência, como a água; desertificação de algumas regiões; efeito estufa, dentre outros (GUIMARÃES; VIANA; COSTA, 2015).

As mudanças ocorridas na sociedade foram capazes de transformar uma pequena parcela da população, o modo pelo qual elas pessoas agiam em relação ao meio ambiente, e consequentemente a forma que as empresas passaram a agir. O que se nota agora é justamente o contrário; as empresas tomaram conhecimento da importância do meio ambiente e, agora, através do marketing, buscam conscientizar os consumidores que ainda não se atentaram para essa realidade (GUIMARÃES; VIANA; COSTA, 2015).

A realidade existente hoje no que se referem aos custos enfrentados pelas empresas só vem aumentando. Os custos das matérias primas utilizadas no processo produtivo estão cada vez mais altos, o que acaba gerando custos para os consumidores também. Uma solução viável para sanar essa problemática seria a busca por uma oferta sustentável, garantindo, assim, uma crucial vantagem competitiva (KOTLER; KARTAJAIA; SETIAWAN, 2012).

As empresas precisam estar atentas aos processos de mudança que ocorrem no mundo a todo o momento. Elas podem sofrer diversas consequências se não acompanharem esse desenvolvimento de ideias, tendências, que surgem com o passar do tempo. E com a questão sustentável não poderia ser diferente. Dessa forma pensando na prosperidade que essa nova ideia pode trazer e, também em beneficiar o meio ambiente, as empresas deram início a um processo de transformações em suas práticas. E, consequentemente, atraíram clientes que se identificavam com as atitudes desenvolvidas por essas empresas (GUIMARÃES; VIANA; COSTA, 2015).

O pequeno grupo que vai contra a maioria passiva em relação aos abusos das indústrias contra o meio ambiente é conhecido como consumerista. Os consumeristas são um grupo formado por cidadãos conscientes que exigem maiores informações às indústrias sobre o método pelo qual estas vêm utilizando no processo produtivo e realização de serviços. Esse novo tipo de consumidor são pessoas que além de se preocupar com a qualidade dos produtos ou serviços adquiridos também se interessam em saber do processo pelo qual passaram analisando assim possíveis danos que estes causaram ao meio ambiente (KLAIN; NAIME, 2012).

É possível observar que através do movimento consumerista está surgindo grupos fortes de consumidores que perceberam que podem ir contra o poder de empresas que não possuem um conceito ecológico através do seu poder de compra. Com isso percebem a importância de apoiar empresas que possuem um critério ambiental, em vez de empresas que não os possuem. Diante disso passam a praticar o consumo consciente, ou consumo verde (KLAIN; NAIME, 2012).

No entanto, promover o consumo sustentável vai além de só estabelecer mudanças no comportamento, na aparência dos produtos ou até mesmo uma forma diferente de realizar um serviço ao consumidor (GONÇALVES-DIAS; TEODÓSIO, 2012). A proposta da 
sustentabilidade necessita que haja uma transformação profunda de conscientização dos colaboradores em termos de cultura, comportamento e postura (DALLAS, 2009).

Os problemas ambientais são hoje bem mais observados que antes. Campanhas ambientais possuem muito mais apoio da população, isso porque os consumidores estão cada vez mais atentos aos produtos que vem comprando e onde estão sendo comercializados. Os consumidores estão cada vez mais conscientes de que a maioria dos problemas ambientais enfrentados pela população hoje tem referência à introdução desses produtos no mercado consumidor. A mudança no comportamento dos consumidores levou ao surgimento de um novo tipo de marketing, o marketing verde (KLAIN; NAIME, 2012).

\subsection{Marketing}

O marketing é o processo que está diretamente ligado a todo o processo produtivo, pois tem como finalidade planejar, criar e executar a definição de produtos ou serviços, determinar preços, distribuição e promoção de ideias com o objetivo de proporcionar trocas capazes de satisfazer as necessidades individuais e organizacionais (CHURCHILL; PETER, 2005).

$\mathrm{O}$ marketing pode ser conceituado também como um processo gerencial, combinado a técnica que visa à sobrevivência das organizações por meio da troca voluntária de valores, buscando satisfazer a necessidade e garantir os benefícios de todos os envolvidos no processo de troca (AMARAL, 1996). Fazer marketing significa construir uma identidade própria, tornála a mais genuína possível para que se transforme numa marca forte (KOTLER; KARTAJAIA; SETIAWAN, 2012).

O marketing está relacionado com todas as interações passíveis de ocorrer entre a empresa, o cliente e o ambiente onde se encontram inseridos. Assim, o marketing cuida de satisfazer desejos e necessidades dos consumidores, proporcionar o alcance de objetivos tanto das empresas, quanto dos clientes, além de pensar na responsabilidade social (LAS CASAS, 2001).

A utilização das estratégias de marketing traz inúmeros benefícios às empresas, dentre elas destacam-se o aumento das vendas e, consequentemente, dos lucros, atrai novos clientes, fideliza os já existentes, além de suprir suas necessidades e desejos. Quando utilizadas da maneira correta, as ferramentas de marketing aumentam a demanda decorrente de produtos ou serviços o que por sua vez criam novos postos de trabalho (LAUERMANN; de PAULA; TOKARS, 2017).

O marketing também está relacionado à ideia de entrega de valor ao cliente. Diante de um cenário extremamente competitivo, em que os consumidores estão cada vez mais racionais, a empresa precisa oferecer um valor superior em seus produtos. O marketing existe para cuidar dos interesses da empresa e do consumidor, desse modo deve satisfazer as necessidades e desejos dos clientes além de obter lucro para a empresa (PORTELA, 2001). E um cliente satisfeito é aquele que ao consumir um produto ou serviço percebe uma qualidade superior no bem/serviço adquirido.

A atividade de marketing não deve ser vista como um método utilizado com o propósito de vender produtos e gerar lucros, o marketing é muito mais que isso e está relacionado ao desenvolvimento da produção e desenvolvimento de serviços, além de ser o responsável pela exposição destes ao mercado consumidor. É dever de o marketing influenciar o comportamento do mercado consumidor (OLIVEIRA, 1985).

Toda e qualquer empresa funciona porque existem os consumidores, e buscar a satisfação desses clientes deve ser o principal foco das organizações. Eles trazem crescimento e desenvolvimento para as organizações e estar atento às suas necessidades é algo de fundamental importância. Diante das incertezas e competitividade existentes no mercado e que rodeiam as empresas, torna-se uma tarefa diária de empresas que querem ter um diferencial 
competitivo, estarem atentas as necessidades dos clientes, saber identificar e buscar atender a essas necessidades (ALMEIDA et al., 2014).

As empresas devem perceber que focar na qualidade do atendimento prestado a seus clientes é essencial como uma boa tática de estratégia de marketing, visto que um cliente que tem suas necessidades atendidas sempre voltará a comprar e ainda se torna um propagador do serviço (LAS CASAS, 2012). Os desejos e necessidades dos consumidores surgem devido a uma motivação, um impulso. E é papel do profissional de marketing saber identificar de onde surgiu esse impulso e assim buscar satisfazer essas necessidades (PORTELA, 2001).

E podem sanar essas necessidades através da oferta de produtos e serviços que atenda todas as suas expectativas (ALMEIDA et al., 2014). As organizações também devem observar as ações de seus concorrentes, perceber se está oferecendo mais valor e satisfação a seus clientes do que a concorrência. A empresa deve colocar suas estratégias acima das da concorrência, alcançando mais vantagem competitiva (TORRES; FONSECA, 2012).

E o cuidado com o meio ambiente é algo que pode gerar vantagem competitiva para as empresas, pois elas terão uma produtividade mais alta. O processo produtivo vai consumir menos recursos e lançar uma menor quantidade de resíduos, além da matéria prima que será utilizada que é mais sustentável. E o papel do marketing nesse processo é bem mais fácil, pois os próprios consumidores atuarão como canais para os outros reduzindo o custo com o marketing, o que fará com que o custo da empresa com a aquisição de clientes também será reduzido visto que práticas sociais e ecológicas possuem alto grau de aceitação (KOTLER; KARTAJAIA; SETIAWAN, 2012).

O envolvimento das empresas com as causas ambientais está diretamente ligado a um novo modo de consumo, a um novo tipo de consumidor, em atender as necessidades desse novo modo adquirido por eles, assim como a crescente cobrança da sociedade com os impactos ambientais. E é com o marketing que as empresas buscam satisfazer essa necessidade da população por produtos com baixo impacto ambiental, que tenha seu processo produtivo ecologicamente correto, ou seja, que inclua a produção, comercialização, consumo e descarte (KLAIN; NAIME, 2012).

\subsection{Marketing Verde}

O marketing verde pode ser conceituado como um conjunto de políticas que são utilizadas, estrategicamente, pelas empresas com o objetivo de transmitir aos consumidores o diferencial em seu produto, buscando-se, assim, conquistar um mercado-alvo. Tem como função garantir o sucesso da organização em termos de comercialização e, ainda, diminuindo o impacto ambiental. Tem como função, também, orientar, educar e criar desejos e necessidades nos clientes (ENOKI et al., 2008).

Consiste da integração de todas as políticas adotadas pelo marketing, adicionando-se a elas cuidado com o meio ambiente. Com isso, as estratégias se intensificam quando o objetivo é influenciar na conscientização dos consumidores com relação às práticas ambientais (BAROTO, 2007). Dessa forma o marketing verde propõe oferecer produtos e serviços que não agridam o meio ambiente, por preservar os recursos naturais e gerar menos impacto ambiental no processo produtivo, além de conscientizar a população a agir de maneira ecologicamente correta e ao público mais jovem a importância de tomar essas decisões agora e no futuro (KLAIN; NAIME, 2012). Os produtos verdes podem ser diferenciados dos produtos convencionais pelo fato que estes geralmente apresentam-se como produtos com maior desempenho e os produtos sustentáveis se superam em benefícios ao meio ambiente (AFONSO, 2010).

O marketing verde possui dois objetivos: pensar produtos que satisfaçam tanto as necessidades do consumidor quanto as do meio ambiente e; determinar para o produto verde 
uma imagem de qualidade, reforçando a sensibilização para a sustentabilidade (OTTMAN, 1994). O processo de implementação da temática verde aos produtos requer muito planejamento, pois as mudanças envolvidas são definitivas. Tudo que se utilizava até então deve ser inutilizado para que não ocorra comprometimento da qualidade ambiental do que está sendo produzido agora (BAROTO, 2007).

$\mathrm{Na}$ estratégia do marketing verde, a empresa possui o objetivo de vender, assim como preocupar-se com o impacto que o produto vendido pode causar no meio ambiente. Levando em conta tanto o processo de fabricação, quanto o descarte após o seu consumo (PEREIRA, 2011). A adoção do marketing verde pelas empresas vai além de pensar produtos e revendê-los sem que gerem impactos ambientais. É preciso que exista uma relação solidificada entre consumidor, empresa e meio ambiente. A implementação do marketing verde requer que haja a percepção macro do processo. Assim, não só precisa estar consciente da importância dessa abordagem, mas também todos os outros envolvidos clientes internos e externos (DIAS, 2009).

A gestão do marketing verde nas empresas traz inúmeros benefícios, tanto estratégicos quanto econômicos. Os benefícios estratégicos incluem: inovação do portfólio de produtos, reestruturação de relações com a comunidade, órgãos governamentais e grupos ambientalistas, nova imagem constitucional e; maior produtividade. Beneficiam-se economicamente, com a redução do consumo de matérias-primas, como água, energia e outros insumos; obtendo uma linha de novos produtos para novos mercados e; maior participação no mercado com a implantação de novos produtos (GERN, 2012).

\subsection{Consumidores Verdes}

Os consumidores podem e devem ser considerados como peças-chave no processo de venda de qualquer organização, principalmente no que diz respeito ao consumo de produtos sustentáveis. Dessa forma, é importante entender que o consumidor tem suas preferências na hora de decidir o que vai comprar, principalmente se este produto for considerado um produto sustentável (COLARES; MATTAR, 2016).

Os consumidores verdes consomem com o objetivo de melhorar o mundo, é característica de esses clientes terem um consumo consciente, talvez por conta disso sejam vistos como clientes que consomem pouco quando na verdade apenas consomem de maneira diferente (BARBOZA; ARRUDA FILHO, 2012). O consumidor verde além de levar em consideração as variáveis como preço e qualidade, também focam no meio ambiente com uma questão importante. Para esses consumidores os produtos sustentáveis devem ter seu processo produtivo livre de procedimentos que afetem o meio ambiente (LAYRARGUES, 2000).

Os consumidores que possuem o hábito de consumir produtos verdes pensam na utilidade desse produto para seu uso pessoal e também na utilidade deste para o meio ambiente. São consumidores com valores adquiridos em longo prazo (DIAS, 2007). Para as empresas é importante tratar bem esse consumidor, levando em conta que eles ajudam na disseminação da ideia ambiental podendo influenciar outros consumidores que compartilhem da mesma causa (VEIGA NETO et al., 2014).

\section{METODOLOGIA}

A presente pesquisa foi desenvolvida na cidade de Parnaíba-PI entre março e novembro de 2018 e teve como objeto de análise três supermercados locais, reconhecidos no estudo como organizações A, B e C. O estudo foi realizado visando responder ao problema de pesquisa: como questão norteadora: como ocorre o envolvimento do marketing verde na escolha de compra dos consumidores em supermercados? 
No que se refere ao tipo de pesquisa, caracteriza-se como exploratória, de abordagem qualitativa. Os procedimentos utilizados para de coleta de dados foi o método da entrevista semiestruturada, observação indireta não participante e análise documental. E como método de análise de dados, foi utilizado o estudo de caso múltiplo.

O roteiro de entrevista aplicado entre os meses de setembro e outubro de 2018 utilizado no estudo em questão foi composto por 10 (dez) perguntas abordando em seu contexto, assuntos como a sustentabilidade e sua importância, a utilização do marketing nos supermercados, implantação do marketing verde, o hábito de compra dos consumidores levando em consideração sua relevância em relação aos produtos sustentáveis, importância e vantagem dos produtos sustentáveis sob a ótica dos stakeholders. Após a realização das entrevistas, foi realizada a transcrição de seu conteúdo para o devido tratamento dos dados.

Os métodos de observação e análise documental foram utilizados com o objetivo de buscar confrontar informações obtidas com a técnica da entrevista. Dessa forma, foi observada tanto a estrutura do ambiente em si, a disposição dos produtos voltados à temática verde, quanto o comportamento e atitudes dos participantes das entrevistas. E para o levantamento documental utilizou-se de informações retiradas dos sites e redes sociais das empresas estudadas.

\subsection{Sujeitos da Pesquisa}

Os métodos de entrevista e observação foram realizados com os stakeholders das organizações estudadas. O grupo pesquisado constitui-se dos gestores, fornecedores, colaboradores e consumidores. Os entrevistados são identificados ao longo do estudo através da letra E, seguido do número estabelecido a partir da ordem das entrevistas.

Dessa forma, foram entrevistados 21 stakeholders (quadro1), de modo que foram entrevistados 1 gestor, 2 fornecedores, 2 funcionários e 2 clientes de cada organização, onde todos assinaram o Termo de Consentimento Livre e Esclarecido autorizando a utilização das informações prestadas, assim como foi apresentado ao responsável das empresas a Carta de Apresentação permitindo o desenvolvimento do estudo.

\begin{tabular}{|c|l|}
\hline Entrevistado & \multicolumn{1}{|c|}{ Função } \\
\hline E1 & Gestor da Empresa A \\
\hline E2 & Gestor da Empresa B \\
\hline E3 & Gestor da Empresa C \\
\hline E4 & Fornecedor da Empresa A \\
\hline E5 & Fornecedor da Empresa A \\
\hline E6 & Fornecedor da Empresa B \\
\hline E7 & Fornecedor da Empresa B \\
\hline E8 & Fornecedor da Empresa C \\
\hline E9 & Fornecedor da Empresa C \\
\hline E10 & Funcionário da Empresa A \\
\hline E11 & Funcionário da Empresa A \\
\hline E12 & Funcionário da Empresa B \\
\hline E13 & Funcionário da Empresa B \\
\hline E14 & Funcionário da Empresa C \\
\hline E15 & Funcionário da Empresa C \\
\hline
\end{tabular}




\begin{tabular}{|l|l|}
\hline E16 & Consumidor da Empresa A \\
\hline E17 & Consumidor da Empresa A \\
\hline E18 & Consumidor da Empresa B \\
\hline E19 & Consumidor da Empresa B \\
\hline E20 & Consumidor da Empresa C \\
\hline E21 & Consumidor da Empresa C \\
\hline
\end{tabular}

Quadro 1: Stakeholders entrevistados Fonte: Dados da pesquisa

\subsection{Abordagem da Pesquisa}

As pesquisas exploratórias são consideradas de baixa complexidade em seu planejamento. É escolhida quando o tema a ser estudado é pouco conhecido, sendo difícil formular hipóteses objetivas sobre ele. É comum como métodos de coleta nessa pesquisa o levantamento bibliográfico e documental, entrevistas e como análise de dados, os estudos de caso (GIL, 2008).

A pesquisa qualitativa está relacionada à compreensão de determinado conhecimento. Os pesquisadores que preferem utilizar-se da pesquisa qualitativa estão em busca de esclarecer o porquê das questões, tendo em vista que os valores não podem ser quantificados ou provados com fatos. São aspectos que predominam nas relações sociais (GERHARDT; SILVEIRA, 2009).

A abordagem qualitativa acredita que a ciência deve analisar aspectos não quantificáveis também. Esse método pauta-se nas ciências sociais, que defende o fato de que a subjetividade deve ser objeto de investigação. Dessa forma, a abordagem qualitativa busca entender as interações desenvolvidas entre o homem e o meio em que está inserido (SOUZA; KERBAUY, 2017).

\subsection{Procedimentos Metodológicos}

Seu procedimento será um estudo de caso múltiplo da compreensão do envolvimento do marketing verde na escolha de compra dos consumidores em supermercados. Estudos de caso comportam definições diferenciadas, quando o objeto de investigação difere. Assim, pode ser definido de maneira técnica, primeiro, como uma investigação prática em que se busca saber sobre um evento dentro do seu contexto real, principalmente quando não há uma transparência no limite entre eles. Possui métodos muito abrangentes, reunindo informações específicas tanto para a coleta de dados, quanto para a análise de dados (YIN, 2001).

É um método diferenciado, que pode ser utilizado nos mais variados tipos de trabalhos. Geralmente é utilizado com o objetivo de descrever alguma situação atual de ocorrências sociais buscando saber como ou porque acontecem (ANDRADE et al., 2017). É uma estratégia de pesquisa que traz muita contribuição às pesquisas que utilizam esse método. Essa estratégia serve para esclarecer conteúdos que se englobam o universo individual, organizacional, social e político (YIN, 2001).

Tratando-se de estudo de caso múltiplo, pontua-se que essa metodologia é uma das mais contendedoras na pesquisa, visto que, se trata de uma alternativa empírica para se averiguar fenômenos da atualidade, sendo essa ação realizada de forma profunda e sob circunstâncias reais. (YIN, 2001).

No estudo em questão, a utilização do estudo de caso proporcionou esclarecer a relação existente entre as estratégias de marketing verde voltado ao mercado consumidor e a realidade que está por trás disso. Esse método tem como objetivo explicar tal fenômeno, trazendo 
elucidações a respeito do objeto de estudo, no caso marketing verde e, a realidade em seu contexto, o mercado consumidor.

Com o objetivo de melhor validar o estudo de caso, buscou-se na técnica de triangulação de dados trazerem uma convergência dos métodos de coleta de dados. Esse método consiste em reunir diferentes métodos tanto de coleta como de análise de dados com o objetivo de dar mais fundamentação para os resultados obtidos na pesquisa. É necessário analisar os resultados encontrados a partir de todos os métodos que foram utilizados (ZAPPELLINI; FEUERSCHÜTTE, 2015).

\subsection{Métodos de Coleta de Dados}

Em relação à técnica realizada para coleta de dados, enquadra-se no método de Observação Direta Intensiva. O método utilizado inclui duas técnicas de coleta de dados: a observação e a entrevista. A classificação de observação utilizada é a observação nãoparticipante e o método da entrevista, foi a semiestruturada.

Esse tipo de técnica prevê a organização previa de um roteiro com questões ligadas ao tema a ser estudado, no entanto, permitindo que o entrevistado se sinta à vontade para se expressar além do que lhe foi questionado (GERHARDT; SILVEIRA, 2009). Pode combinar perguntas abertas e fechadas, o entrevistador tem a missão de direcionar o assunto para o tema em questão sempre que julgar necessário ou até adicionar questões para maior esclarecimento. (MIRANDA, 2009).

Caracterizam-se como um tipo de método que se agrupam em categorias dependendo da estrutura em que está organizada. O método da entrevista é muito utilizado para coleta de informações em pesquisas das ciências sociais. Trata-se de uma conversação entre duas pessoas e cujo objetivo é a obtenção de dados por parte de uma delas a respeito de determinado conteúdo (LAKATOS; MARCONI, 2003).

A entrevista trata-se de uma técnica eficaz quando o objetivo do entrevistador busca obter, além dos resultados propostos em seus objetivos, percepções pressupostas ao comportamento como atitudes, sentimentos e valores. Com isso, o pesquisador pode incorporar à sua pesquisa uma maior riqueza de informações (RIBEIRO, 2008).

No entanto, é importante observar que o método da entrevista para ser mais eficaz, aconselha-se a sua utilização acompanhada de outro método de análise para que se possa garantir a transparência dos resultados que se deseja obter (BRITO JR.; NAZIR JR, 2011). Com isso, busca-se utilizar juntamente ao método da entrevista a técnica da observação não participante.

No método de observação não-participante, o observador embora tenha contato com a situação a ser estudada, não faz parte dela diretamente, permanece fora do contexto. Sua postura diante do objeto de estudo é completamente informal, age apenas como um espectador. Mesmo de fora da situação, o pesquisador detém controle sobre o andamento do processo e seu desenvolvimento (LAKATOS; MARCONI, 2003).

A utilização do método de observação indireta torna-se mais eficaz quando é dirigida a constatar fatos de natureza pública ou que não sejam exclusivamente privadas, pois esse método objetiva verificar ações de cunho social como comportamentos, hábitos, modo de vestimentas etc. Esse método possui muitas vantagens como, quando bem feita, não alterar o resultado da pesquisa (GIL, 2008).

A utilização da pesquisa documental permite ao investigador a coleta de dados através de materiais relacionados ao seu problema de pesquisa, que podem ser escritos ou não (LAKATOS; MARCONI, 2003). Essa pesquisa trabalha tanto com documentos que ainda não foram analisados de uma maneira científica, quanto com materiais que alguma forma já foi analisada, considerada como uma fonte mais formalizada (GIL, 2008). O estudo, ao utilizar-se 
dos métodos de coleta de entrevista e observação indireta, propõe obter informações mais completas acerca do tema em questão. A aplicação das técnicas foi voltada aos gestores, fornecedores, colaboradores e consumidores.

\subsection{Métodos de Análise de Dados}

Seu procedimento de análise de dados foi baseado nas 10 (dez) perguntas da entrevista com 21 stakeholders das organizações A, B e C estudadas. As entrevistas foram realizadas individualmente com cada um e filmadas para posterior transcrição. Cada um desses stakeholders entrevistados assume um papel diferente por uma finalidade conforme apresentado no quadro 1 (um) da sessão 3.1 Sujeitos da pesquisa. Através dos dados obtidos com as entrevistas e observação foi possível a análise dos dados coletados que serão discutidos na sessão a seguir divididos em sessões conforme os objetivos desse estudo.

\section{ANÁLISE E DISCUSSÃO DOS RESULTADOS}

Os resultados encontrados na pesquisa estão divididos em subseções, de acordo com os objetivos que se buscou alcançar. Dessa forma são apresentados os dados sobre a relação existente entre os consumidores e os produtos sustentáveis; a prática de compra dos consumidores sob o ponto de vista dos stakeholders; a percepção dos stakeholders sobre a estratégia de marketing verde e; a importância do marketing verde para as organizações.

\subsection{Relação entre Consumidores e Produtos Sustentáveis}

O Consumo sustentável é o ato de adquirir, utilizar e descartar bens e serviços com respeito ao meio ambiente e à dignidade humana. Consumir Sustentavelmente quer dizer saber usar os recursos naturais para satisfazer as nossas necessidades, sem comprometer as necessidades das gerações futuras (MACHADO, 2011).

Sobre a relação existente entre os consumidores e os produtos sustentáveis, o que se percebe é que o consumo sustentável é uma atitude comum para alguns consumidores, no entanto ainda é considerada grande a parcela da população que desconhece o verdadeiro significado da questão ambiental quando relacionada a produtos verdes.

Apenas depois de se explicar sobre a temática estudada é que os entrevistados respondem sobre o assunto. O consumo de produtos sustentáveis está, aos poucos, se tornando uma realidade, mas a relação existente entre consumidores e produtos sustentáveis ainda deixa a desejar.

A partir dos dados analisados, constatou-se que o consumo dos produtos sustentáveis ainda é pouco. Uma das possíveis causas dessa situação está no fato de que esses produtos possuem um custo considerado, relativamente alto. Além disso, falta também conscientização por parte das pessoas.

É o que se afirma na declaração feita pelo gestor da organização B quando questionado a respeito do tipo de produto consumido pelos clientes:

"São consumidos mais os comuns, o produto sustentável está ganhando espaço aos poucos. No entanto, já se percebe um aumento relativo no que se refere a esses produtos como pães, massas e cereais. Uma das razões para isso pode estar relacionada ao custo e a outra razão é o fato das pessoas não se conscientizarem da importância e necessidade desse consumo" (E2). 
Diante dos problemas enfrentados pela humanidade em relação ao meio ambiente, é perceptível o aumento de pessoas adotando um comportamento mais sustentável, deixando, por exemplo, de consumir produtos que prejudicam o meio ambiente. São esses consumidores que auxiliam na disseminação do conceito de proteção ao meio ambiente (SANTOS 2017).

Na visão do fornecedor da empresa A, os produtos sustentáveis são mais procurados por clientes que possuem algum entendimento sobre os mesmos.

\section{"A maioria dos clientes não consomem esses produtos, são poucos os clientes que procuram por esses produtos, apenas aqueles clientes que entendem mais" (E5).}

Ainda com base no que foi analisado sobre a relação existente entre os clientes e os produtos verdes, percebeu-se que os entrevistados concordam com a importância desses produtos tanto para a saúde, como para o meio ambiente. É o que pode ser contextualizado na visão do funcionário da empresa $\mathrm{A}$, quando questionado sobre a importância do consumo dos produtos sustentáveis:

"Sim, é importante. Porque todos se beneficiam. Tanto a natureza, quanto as pessoas, pois eles também são naturais" (E10).

Reforça essa ideia o cliente da empresa A, quando questionado se esses produtos trazem alguma vantagem:

"Sim. Trazem muita vantagem, por exemplo, no caso de sacolas que são biodegradáveis que em pouco tempo são eliminadas do meio ambiente” (E16).

As vantagens apresentadas pelos produtos verdes são inúmeras. São produtos que oferecem uma vida mais completa e com uma maior expectativa de saúde, além de ser uma chance para melhorar o ambiente em que vivemos (GONZAGA, 2005).

Os consumidores têm uma relação estreita com os produtos sustentáveis, consideram que esses produtos são importantes e que seu consumo traz vantagens, no entanto o consumo ainda é considerado insuficiente. Em estudo realizado por Mendes et al. (2016) "Os resultados alcançados apontam que os consumidores analisados não possuem atitudes que sugiram cuidados ou preservação com o meio ambiente". Diante disso, percebe-se a necessidade de conscientização dessa parcela da população para a prática da sustentabilidade.

\subsection{Práticas de Compra dos Consumidores na Visão dos Stakeholders}

A cada dia o estudo das necessidades, desejos e práticas de compras dos consumidores é considerado mais importante para que as empresas possam executar ações eficazes e eficientes (TARIGO et al., 2016). Sobre as práticas de compra dos consumidores, o que se nota é que os stakeholders apontam um consumo voltado, essencialmente, para as necessidades básicas. Ainda assim é possível notar a existência de clientes que preferem consumir os produtos sustentáveis. Diante das declarações obtidas dos fornecedores das empresas A e B, quando questionados sobre como percebem o tipo de hábito de compra dos consumidores, destaca-se:

\footnotetext{
"Os consumidores procuram produtos mais baratos. Eles visam mais a economia e consomem produtos básicos e essenciais" (E4).

"É muito variado. Têm clientes que consomem produtos mais caros, outros consomem coisas mais em promoção. E os produtos são alimentos como o arroz, feijão, café, são os que saem mais" (E6).
} 
Durante o estudo realizado, percebeu-se que a grande maioria dos consumidores entrevistados pertence a uma parcela da população com características socioeconômicas incompatíveis com o consumo desses produtos, o que pode ser um fator para o baixo consumo desses itens. É o que se assemelha ao estudo realizado por Porto (2012), onde os resultados obtidos mostram, de um modo geral que aspectos relacionados a fatores sociodemográficos explicam razoavelmente a diferença no comportamento dos consumidores às questões relacionadas à responsabilidade social, ambiental e reciclagem.

Ao ser oferecido um produto ou serviço ao cliente, à empresa deve estar atenta ao seu consumidor levando em conta que este possui um perfil próprio de preferências, necessidades. O comportamento de compra dos consumidores é algo bem relativo, tendo como parâmetros os estímulos a que são expostos nas organizações, pois cada pessoa pode e reage de modos diferenciados. Portanto, as empresas estão oferecendo uma quantidade bem diferenciada de produtos a fim de atender bem o seu cliente (TEIXEIRA, 2015).

É o que ressalta o gestor e fornecedor da empresa $\mathrm{C}$ ao afirmarem a existência de uma parcela na população que consome esses produtos:

\footnotetext{
“Os produtos comprados pelos clientes são na maioria produtos comuns, mas têm sempre aqueles que estão dispostos a pagar por produtos mais caros" (E3).

"Talvez isso aconteça pelo conhecimento sobre o produto e também pela condição financeira de pagar por ele" (E8).
}

Alguns clientes, no entanto, sempre estão mais propensos a pagar por um produto aparentemente sem relevância e, dessa forma, são esses os clientes mais aptos a adquirir produtos sustentáveis uma vez que estão mais dispostos a pagar mais caro por produtos que querem consumir (FERRAZ, 2016).

E existe ainda o fato de que consumidores que recebem informações a respeito das questões ambientais mudam sua perspectiva. Esses consumidores geralmente terão reduzida sua satisfação em consumir um produto considerado mais poluente, reduzindo assim seu consumo para esses produtos (COLARES; MATTAR, 2016).

Dessa forma é importante que as empresas tenham conhecimento sobre o hábito de compra dos clientes e o quanto estão dispostos a pagar por determinado produto, pois cada cliente têm preferências próprias. As questões que podem ajudar a entender um pouco a respeito desse hábito estão relacionadas ao costume de onde vivem circunstâncias econômicas, assim como os cargos e salários (BERNARDO; FERREIRA; MARTINS, 2015).

\subsection{Percepções dos stakeholders sobre a estratégia de marketing verde}

O Marketing Verde está diretamente ligado à sustentabilidade. As organizações estão utilizando cada vez mais Marketing Verde como estratégia em seus negócios, possibilitando à divulgação de ações sustentáveis, o cumprimento da legislação ambiental, a exposição do foco nas necessidades e desejos de seus clientes e na conscientização da preservação do meio ambiente (BAROTO, 2007).

No que diz respeito ao marketing verde, é possível notar que existem ações nas empresas referentes à temática, no entanto, estas não são realizadas de modo a atrair a atenção dos consumidores. Quando questionados sobre a existência de um marketing desenvolvido para a preservação do meio ambiente, um fornecedor e um funcionário da empresa A enfatizaram:

\footnotetext{
"Não sei informar, mas a empresa costuma oferecer poucas sacolas para os clientes, reaproveitar sacos que seriam jogados fora, como embalagens de arroz" (E5).

"Não de forma específica. Os produtos sustentáveis não são colocados para as pessoas de um modo adequado. O marketing é feito junto com os outros" (E10).
} 
Diante do que menciona o fornecedor e o funcionário da empresa $\mathrm{A}$, assim como o gestor da empresa B, constata-se que tanto a empresa A quanto a B desenvolve ações similares em relação ao reaproveitamento de materiais. Embora as práticas desenvolvidas pela empresa B trabalhe também a questão social. Complementa o gestor B:

\begin{abstract}
“As ações realizadas é a utilização de papelão, sacos plásticos, que são enviados para uma empresa especializada em reciclagem localizada em Fortaleza. Com os sacos, por exemplo, a empresa fabrica as sacolas plásticas recicladas. É uma parceria que beneficia as duas empresas. Em relação às frutas e verduras, são selecionadas aquelas ainda em bom estado e doadas para instituições" (E2).
\end{abstract}

Para as empresas, desenvolver o marketing verde e repassá-lo aos clientes vai além de só mostrar sua importância, percorre toda a cadeia produtiva, considerando o percurso que vai desde a fabricação, a interação com os fornecedores e distribuidores, e principalmente a decisão de compra dos consumidores (FIGUEIREDO, 2010).

A partir disso, houve a necessidade de saber a opinião dos entrevistados a respeito da implantação do marketing verde nos supermercados como estratégia de conscientização para preservação do meio ambiente. $\mathrm{O}$ fornecedor e o funcionário da empresa $\mathrm{B}$ consideram que:

\footnotetext{
"Seria bom porque ajudaria a separar os produtos sustentáveis dos outros, ajudando as pessoas a conhecerem" (E6).

"Talvez ajudasse no consumo dos produtos sustentáveis, as pessoas poderiam comprar mais" (E12).
}

A implantação do marketing verde é importante para as empresas porque os consumidores não estão preocupados apenas com questões a respeito do preço, qualidade ou prazo de entrega. Saber de onde vêm os produtos que estão consumindo também é algo com que se importam, assim como se as empresas possuem a responsabilidade socioambiental; sendo que empresas envolvidas nessas iniciativas sustentáveis serão mais competitivas aos olhos desses consumidores (INHESTA; CARRIJO, 2015).

Para esse processo de implantação do marketing verde, faz-se necessário que a empresa ajuste todo o seu sistema, tanto na questão de valores, quanto no gerenciamento, no sentido de proporcionar que essa ideia chegue a todos os envolvidos. Portanto, o marketing verde exige uma gestão que atue de modo inter-relacionado gerando os resultados esperados. (LIMA NETO, 2008).

\title{
4.4 Importância do marketing verde para as organizações
}

O marketing verde é uma estratégia de valorização dos produtos sustentáveis, tornandose extremamente importante para as organizações, pois uma empresa que se mostra preocupada com o meio ambiente é uma empresa bem vista pelos consumidores. O marketing verde é importante para as organizações porque se traduz numa oportunidade de mudança de hábitos levando em conta todo o ciclo que envolve a temática verde. Dessa forma, ele se torna uma estratégia capaz de elevar as empresas em relação aos seus concorrentes, por meio da vantagem competitiva (EIDT; CARDOSO; ROMAN, 2017).

$\mathrm{O}$ fornecedor e o funcionário da empresa A apontam a importância do marketing verde para as organizações quando questionados sobre a implantação do marketing verde nas empresas:

"É importante porque faz os consumidores conhecerem outras opções de produtos e ainda ajudar o meio ambiente"(E4). 
"Seria ótimo, porque às vezes a empresa tem esses produtos e os clientes não conhecem" (E10).

Para eles, além da importância do marketing verde para o desenvolvimento das organizações perante seu mercado consumidor, é importante também porque é capaz de disseminar a relevância dos produtos verdes para clientes que talvez ainda não os conheça.

Assim como o marketing convencional, essa outra extensão do marketing, objetiva proporcionar aos clientes e consumidores, assim como às empresas, satisfação e benefícios no processo de trocas que envolvem essas relações. Somado a isso, o marketing verde também busca trazer vantagens principalmente ao meio ambiente que é a base para que tudo isso ocorra. Assim, o marketing verde representa uma verdadeira revolução na maneira de produzir e consumir (LIMA NETO, 2008).

$\mathrm{O}$ fornecedor entrevistado da empresa $\mathrm{C}$ reafirma essa importância ao declarar que essa vertente do marketing vai bem além da relação existente entre empresa e cliente:

“A implantação do marketing verde é importante. É como se as empresas tivessem ajudando não só os clientes, mas também todo o planeta” (E9).

O marketing verde contempla a sociedade de um modo geral. É um método de tomada de decisão e mudança de realidade que permite às organizações beneficiar não só seus clientes ou futuros clientes e sim todos aqueles que de algum modo se sentem movidos por essa causa, a preservação do meio ambiente (BRANDÃO, 2011).

Quando as empresas pensam em desenvolvimento sustentável, devem lembrar que é um processo longo e que requer a união de todos os envolvidos. Não é uma prática que busca apenas se preocupar com mudanças climáticas, deve considerar as pessoas como peças-chave nesse processo. Dessa forma as empresas devem valorizar seus colaboradores e a sociedade (CAMARGO et al., 2017).

\subsection{ANÁLISE COMPARATIVA}

Esta seção tem por objetivo apresentar uma condensação das declarações feitas pelos stakeholders das três organizações que podem ajudar a entender como ocorre o envolvimento do marketing verde no processo de compra dos consumidores. As declarações são referentes a diferentes perguntas realizadas na entrevista.

\begin{tabular}{|c|c|c|c|}
\hline \multirow{2}{*}{ Função } & \multicolumn{3}{|c|}{ O envolvimento do marketing verde na escolha de compra dos consumidores } \\
\hline & Empresa A & Empresa B & Empresa C \\
\hline Gestor & $\begin{array}{lr}\text { Em nossa empresa } & \text { não } \\
\text { existe a implantação do } \\
\text { marketing verde, no } \\
\text { entanto os produtos } \\
\text { relacionados com a } \\
\text { sustentabilidade } & \text { são } \\
\text { separados dos demais para } \\
\text { serem mais percebidos pelo } \\
\text { cliente. (E1) }\end{array}$ & $\begin{array}{l}\text { Um marketing voltado para } \\
\text { eles não tem, mas os } \\
\text { produtos sustentáveis são } \\
\text { separados dos demais em } \\
\text { gôndolas específicas. (E2) }\end{array}$ & $\begin{array}{l}\text { Existe uma preocupação com } \\
\text { relação à implantação do } \\
\text { marketing verde, até porque } \\
\text { esses produtos têm um custo } \\
\text { mais elevado para a empresa. } \\
\text { Nós precisamos que eles sejam } \\
\text { consumidos. (E3) }\end{array}$ \\
\hline Fornecedor & $\begin{array}{l}\mathrm{Na} \text { empresa em que } \\
\text { trabalho existe o marketing } \\
\text { verde. Trabalho com a }\end{array}$ & $\begin{array}{l}\text { O supermercado separa os } \\
\text { produtos sustentáveis numa } \\
\text { seção só para eles. Só que um }\end{array}$ & $\begin{array}{lcr}\text { Não existe esse tipo de } \\
\text { marketing } & \text { aqui } & \text { nesse } \\
\text { supermercado. Provavelmente, }\end{array}$ \\
\hline
\end{tabular}




\begin{tabular}{|c|c|c|c|}
\hline & $\begin{array}{l}\text { marca Mãe Terra que } \\
\text { fornece produtos integrais e } \\
\text { orgânicos, mas na loja aqui } \\
\text { não percebo isso. (E4) }\end{array}$ & $\begin{array}{l}\text { marketing voltado só para } \\
\text { eles não tem. (E7) }\end{array}$ & $\begin{array}{l}\text { as pessoas que compram foram } \\
\text { incentivadas em outro lugar. } \\
\text { (E9) }\end{array}$ \\
\hline Funcionário & $\begin{array}{l}\text { Os produtos sustentáveis } \\
\text { não são colocados para as } \\
\text { pessoas de um modo } \\
\text { adequado. O marketing é } \\
\text { feito junto com os outros. } \\
\text { (E10) }\end{array}$ & $\begin{array}{l}\text { As estratégias de marketing } \\
\text { que percebo são mais a seção } \\
\text { que é destinada só para esses } \\
\text { produtos (E13). }\end{array}$ & $\begin{array}{l}\text { A empresa não desenvolve } \\
\text { nenhuma estratégia que seja } \\
\text { voltada para a preservação do } \\
\text { meio ambiente. No máximo, } \\
\text { oferecem aquelas sacolas } \\
\text { oxibiodegradáveis e as } \\
\text { orgânicas para vender. (E14) }\end{array}$ \\
\hline Consumidor & $\begin{array}{l}\text { Eu consumo esses produtos } \\
\text { quando dá. } \mathrm{O} \text { valor deles } \\
\text { ainda é muito caro. (E16) }\end{array}$ & $\begin{array}{l}\text { Não consumo. Não tenho } \\
\text { costume. (E18) }\end{array}$ & $\begin{array}{l}\text { Eu sei que os produtos } \\
\text { sustentáveis são importantes, } \\
\text { mas não consumo, porque na } \\
\text { verdade nunca pensei muito } \\
\text { sobre isso. (E20) }\end{array}$ \\
\hline
\end{tabular}

Quadro 2: Análise comparativa entre empresas

Fonte: Dados da pesquisa

Quando analisadas sobre a implantação do marketing verde, as empresas deixam claro que não possuem essa estratégia implantada, no entanto as empresas A e B ainda demonstram se preocupar com a percepção dos clientes sobre esses produtos.

A empresa C, entretanto, demonstra uma preocupação com a implantação dessa estratégia apenas em relação a prejuízos financeiros, pois se não vendem esses produtos acabam retidos na empresa. Ainda assim é possível observar que no site da empresa existe uma declaração a respeito da importância da reciclagem e destinação correta dos resíduos, assim como dados que demonstram a ocorrência dessa ação há, pelo menos, cinco anos.

No que se refere à existência de estratégias pra essa vertente do marketing, stakeholders das empresas B E C afirmam não haver estratégias para esses produtos; a empresa B procura separar esses produtos para uma maior visibilidade, já a $C$ acredita que não existe nenhuma referência para os clientes sobre a importância de consumo desses produtos.

Em relação ao consumo, esses produtos são mais consumidos por stakeholders da empresa $\mathrm{A}$ do que pelas outras organizações. $\mathrm{Na}$ empresa $\mathrm{B}$, dois entrevistados afirmaram consumir esses produtos, e na empresa $\mathrm{C}$ nenhum entrevistado disse consumir esses produtos. A principal razão para não consumirem os produtos verdes é o seu custo ainda elevado.

\section{CONSIDERAÇÕES FINAIS}

O objetivo que se buscou alcançar nesse estudo consiste em compreender o envolvimento do marketing verde na escolha de compra dos consumidores em supermercados. Portanto, é possível afirmar que o objetivo geral foi alcançando assim como os objetivos específicos expostos na introdução deste trabalho, uma vez que de um modo geral, é verdadeiro declarar que embora duas das empresas estudadas tenham práticas voltadas para a preservação do meio ambiente, nenhuma das organizações possuem implantada a estratégia de marketing verde.

Dessa forma, a prática de compra dos clientes que consomem os produtos sustentáveis não é influenciada pelas organizações que fizeram parte do estudo. Considerando os objetivos propostos, foi possível analisar que existe, ainda, uma ponte entre o consumo dos clientes e os produtos verdes. Os fatores analisados para isso estão relacionados às questões de preço, 
divulgação desses produtos que ainda é falha na visão dos stakeholders entrevistados. Foi levantada como hipótese, também, a falta de conscientização por parte das pessoas.

Diante dos dados analisados, percebe-se que as instituições estudadas consideram importante o consumo dos produtos verdes e a divulgação da temática ambiental, mas não praticam essa filosofia visto que mesmo com clientes que se mostram interessados pelas práticas ambientais, as empresas não possuem um planejamento para a satisfação desses clientes.

A realização dessa pesquisa trouxe como contribuições, constatar que a temática ambiental é vista pelos entrevistados como um tema importante e mesmo em pequena quantidade as pessoas acreditam que o consumo desses produtos é bom para todos, além de contribuir com o meio ambiente. E é importante salientar que o estudo contribui também para a pesquisa científica do assunto em questão, servindo assim de base para futuras pesquisas mais aprofundadas sobre a temática.

Diante de tudo que foi mencionado, é natural concluir que se as empresas tivessem interesse em implantar a estratégia de marketing verde esse número de pessoas poderia ser bem maior. Além de suas contribuições evidentes o desenvolvimento desse estudo busca ainda contribuir para os estudos relacionados à temática verde, mediante explanação das opiniões obtidas dos stakeholders participantes desse estudo, além de evidenciar e incentivar a importância da utilização desses produtos.

Os processos do presente trabalho contaram com limitações, como a dificuldade em conseguir informações sobre o marketing verde, produtos verdes. Durante a entrevista, diante de alguns questionamentos, as pessoas não tinham, muitas vezes, esclarecimento sobre esses temas. Além disso, duas das empresas estudadas não se mostraram muito interessadas em contribuir com a realização do estudo, levando em conta que nessas empresas foi necessário a visita por mais de uma vez.

O que se sugere para estudos futuros é que se façam estudos semelhantes a teste focando na razão dessa resistência que as têm em adotar estratégias voltadas para incentivar o consumo de produtos sustentáveis, visto que existe um público para isso a fim de cruzar informações e descobrir novos dados. Seria importante também analisar as razões que levam as pessoas a consumirem esses produtos, já que quando se trata de produtos alimentícios as empresas não costumam focar nesse incentivo através de uma pesquisa quantitativa.

\section{REFERÊNCIAS}

AFONSO, A. C. B. O consumidor verde: perfil e comportamento de compra. Dissertação apresentada ao programa de pós-graduação em mestrado da Universidade Técnica de Lisboa. Lisboa, 2010. Disponível em: <https://www.repository.utl.pt/handle/10400.5/1758>. Acesso em: 30 out. 2018.

ALMEIDA, K. M. et. al. As contribuições do marketing de relacionamento para a fidelização dos clientes da D'Pele Moda Íntima. Revista Brasileira de Pesquisa em Administração, Paraíba, v. 1, n. 1, p. 08 - 17, Jan-Dez, 2014. Disponível em: <https://www.gvaa.com.br/revista/index.php/RBPA/article/view/3602>.Acesso em: 18 abr. 2018.

ALMENDRA, B.F. Consumidor Verde: estudo de caso sobre perfil e características do mercado, São Paulo, 2012.

AMARAL, S. A. Marketing e desenvolvimento profissional em unidades de informação. Ciência da Informação. Brasília, v. 25, n 03, 1996.

ANDRADE, S. R. et al. O Estudo de caso como método de pesquisa em enfermagem: uma revisão integrativa. Texto contexto - enferm.,Florianópolis , v. 26, n. 4, e5360016, 2017 
.Disponível em: $\quad<$ http://www.scielo.br/scielo.php?script=sci_arttext\&pid=S010407072017000400308\&lng=en\&nrm=iso>. Acesso em: 20 de mai. 2018.

BARBIERI. C.J. Gestão ambiental empresarial: conceitos, modelos e instrumentos. 2 ed. São Paulo: Saraiva, 2007.

BARBOZA, M. N. L..; ARRUDA, E. J. M. F. O comportamento do consumidor tecnológico diante dos valores ecologicamente corretos: ideologia verde versus responsabilidade social. Intercom-RBCC, São Paulo, v. 35.n.1.p.157-182, jan./jun.2012.

BAROTO, Anderson. Marketing Verde/ 2007. Faculdade Cristo Rei. Cornélio Procópio - PR. Disponível em: <http://www.faccrei.edu.br/gc/anexos/rvartigos_19. pdf>. Acesso em 13 mar.2019.

BERNARDO. J. M. O Comportamento do Consumidor no Varejo Supermercadista. 2015. Disponível em: <http://www.inovarse.org/sites/default/files/T_15_417.pdf>. Acesso em: 30 out. 2018.

BRANDÃO, M. R. M. et al. Influência dos Stakeholders na adoção de estratégias de marketing verde. Revista Pretexto. Belo Horizonte, v. 12, n. 4, p. 33-54. Out/dez 2011.

CAMARGO, C. R. Gestão do uso de energia e do desempenho inovador sustentável na cadeia de suprimentos da indústria mineral: análise de três empresas. In: AOS - Amazônia, Organizações e Sustentabilidade, v.6, n.2, jul./dez. 2017, p. 133-154. Disponível em: <http://revistas.unama.br/index.php/aos/article/view/764/pdf>. Acesso em: 5 dez. 2018.

CHAVES, F.E. et al. Marketing Verde como Estratégia de Sucesso da Imagem Corporativa. In XI SIMPÓSIO DE EXCELÊNCIA EM GESTÃO E TECNOLOGIA, 2014, Rio de Janeiro. Gestão do conhecimento para a sociedade. Disponível em: <https://www.aedb.br/seget/arquivos/artigos14/3220237.pdf > . Acesso em: 21 mar. 2018.

CHURCHILL, G. A. JR., PETER, J. P. Criando Valor para os Clientes. 2ed. São Paulo: Saraiva, 2005.

COLARES, A. C. V.; MATTAR, P. Produtos Verdes: Análise das Características Potencialmente Influenciadoras dos Consumidores Sustentáveis. REUNIR: Revista de Administração, Contabilidade e Sustentabilidade, v. 6, n. 1, p. 56-73, 29 abr. 2016.

DALLAS, N. Como tornar sua empresa ecologicamente responsável: 24 lições para superar os desafios do aquecimento global (tradução de Bernardo Araújo), Rio de Janeiro, Sextante, 2009.

DIAS, R. Gestão Ambiental: responsabilidade social e sustentabilidade. São Paulo: Atlas, 2009.

DIAS, R. Marketing ambiental: ética, responsabilidade social e competitividade nos negócios. São Paulo: Atlas, 2007.

EIDT, E. C. et al. Marketing Verde e sua Aplicação pelo Composto de Marketing: Uma revisão sistemática. Revista Eletrônica de Administração (Online) ISSN: 1679-9127, v. 16, n.2, ed. 31, Jul-Dez 2017. Disponível em: <https://www.researchgate.net/publication/324031753>. Acesso em: 21 mar. 2018.

ENOKI, P. A. et al. Estratégias de Marketing verde na Percepção de compra dos Consumidores na Grande São Paulo. Revista Jovens Pesquisadores, ano v, n. 8, jan./jul. 2008. Disponível em: <https://www.researchgate.net/publication/277091831>. Acesso em: 20 abr. 2018.

EVANDRO SUPERMERCADO. Disponível em: <https://web.facebook.com/EvandroSupermercado/?_rdc=1\&_rdr>. Acesso em: 29 nov. 2018. FERRAZ, S. B. et al. Produtos verdes: um estudo sobre atitude, intenção e comportamento de compra de universitários brasileiros. Revista de Administração, UFSM, 9(4), 605-623.

FIGUEREDO, G.N. de. O marketing verde no varejo de alimentos no Brasil e na Alemanha: um estudo de caso comparativo entre os supermercados Pão de Açúcar e Rewe. 2010. 96 f. Dissertação (Mestrado em Administração) - Pontifícia Universidade Católica de São Paulo, São Paulo, 2010. 
FÜHR, H. ALLES, K. Marketing Ambiental: Uma Ferramenta Estratégica. Itapiranga, 2008. GERHARDT, T. E.; SILVEIRA, D. T. Métodos de Pesquisa. 1.ed.- Porto Alegre: Editora da UFRGS, 2009.

GERN, T. G.; BEILER, G. Marketing Ambiental: Uma ferramenta estratégica. In: VIII Convibra Administração - Congresso Virtual Brasileiro de Administração. Disponível em: <http://www.convibra.com.br/upload/paper/adm/adm_2899.pdf>. Acesso em: 18 mar. 2018. GIL, A. C. Métodos e técnicas de pesquisa social. 6.ed.- São Paulo: Atlas, 2008.

GONÇALVES-DIAS, S. F.; TEODÓSIO, A. S. S. Controvérsias em torno do consumo e da sustentabilidade: uma análise exploratória da literatura. In: AOS - Amazônia, Organizações e Sustentabilidade, v. 1, n. 2, ago./dez., 2012, p. 61-77. Disponível em: <http://revistas.unama.br/index.php/aos/article/view/37/pdf>. Acesso em: 5 dez. 2018.

GONZAGA, C. A. M. Marketing verde de produtos florestais: teoria e prática. Revista Floresta, Curitiba, v. 35, p. 353-368, 2005.

GUIMARÃES, C. V, COSTA, P. H. Os desafios da Consciência Ambiental: o marketing verde em questão. Ilhéus: C@LEA. Disponível em: <http://www.uesc.br/revistas/calea/edicoes/rev4_artigo7.pdf>. Acesso em: 16 mar. 2018.

INHESTA, A. V.; CARRIJO, J. R. S. Supermercado Verde: Consciência ambiental na área varejista em $2015 . \quad$ Bauru-SP. 2 Disponível <http://www.inovarse.org/sites/default/files/T_15_492.pdf>. Acesso em: 25 out. 2018.

ISO 14000. Série ISO 14000:Normas Técnicas. Disponível em: <https://www.normastecnicas.com/iso/serie-iso-14000/>. Acesso em: 29 nov. 2018.

JÚNIOR, A. F. B.; JÚNIOR, N. F. J. A utilização da técnica da entrevista em trabalhos científicos. Evidencia, Araxá, v. 7, n. 7, p. 237-250, 2011.

KLAIN, S; NAIME, R. Estudo sobre a conscientização do consumidor na prática dos gestos de consumo: estudo de caso com estudantes da universidade de FEEVALE. Rev. Elet. em Gestão, Educação e Tecnologia Ambiental, v 8, no 8, SET-DEZ, 2012.

KOTLER, P; KARTAJAYA, H; SETIAWAN, I. Marketing 3.0: as forças que estão definindo o novo marketing centrado no ser humano. Rio de Janeiro: Elsevier, 2012.

LAKATOS, E. M.; MARCONI, M. A. Fundamentos de metodologia científica. 5.ed. São Paulo: Atlas, 2003.

LAS CASAS, A. L. Marketing de serviços. 6 ed. São Paulo: Atlas. 2012.

LAS CASAS, A. L. Marketing: conceitos, exercícios, casos. 5. ed. São Paulo: Atlas, 2001.

LAUERMANN, B. G; PAULA de, D; TOKARS, E. A importância da utilização do marketing nos centros de estética, 2017. Disponível em: <http://tcconline.utp.br>. Acesso em: 18 abr. 2018.

LAYRARGUES, P.P. Sistemas de Gerenciamento Ambiental, Tecnologia Limpa e Consumidor Verde: a delicada relação empresa-meio ambiente no ecocapitalismo. RAE Revista de Administração de Empresas, São Paulo, v. 40, n. 2, p.80-88, 2000.

LIMA, C. N. A importância do marketing ambiental para as empresas exportadoras brasileiras. Centro de Ciências Sociais Aplicadas - Gestão da Universidade do Vale do Itajaí. 2008. Disponível em: <www.administradores.com.br>. Acesso em: 20 abr. 2018.

MACHADO, Ricardo. Artigo: Consumo Sustentável. Disponível em: < https: //www.ecodebate.com.br/2011/08/31/consumo-sustentavel-artigo-de-ricardo-machado/ >. Acesso em: 13 mar.2019.

MATTOS, S, E. Desenvolvimento sustentável: uma análise histórica. Vitrine da Conjuntura, Curitiba, v.1, n.9, dezembro 2008.

MENDES, J. N. S. et. al. Consumo e sustentabilidade: um levantamento das práticas cotidianas de consumidores na cidade de Campina Grande-PB. In: AOS - Amazônia, Organizações e Sustentabilidade, v. 5, n.1, jan/jun 2016, p. 21-38. Disponível em: <http://revistas.unama.br/index.php/aos/article/view/368/pdf>. Acesso em: 5 dez. 2018. 
MERCANTIL IDEAL. Disponível em: <https://web.facebook.com/pages/MercantilIdeal/219380054848718?_rdc=1\&_rdr>. Acesso em: 29 nov. 2018.

MIKHAILOVA, I. Sustentabilidade: evolução dos conceitos teóricos e os problemas da mensuração prática. Revista Economia e Desenvolvimento, n. 16, 2004.

MIRANDA, R. J. P. Qual a relação entre o pensamento crítico e a aprendizagem de conteúdos de ciências por via experimental?:Um estudo no $1^{\circ} \mathrm{Ciclo}$, dissertação apresentada à Universidade de Lisboa para obtenção do grau de mestre em Educação, na Área de Especialização de Didática das Ciências. Disponível em: <http://repositorio.ul.pt/bitstream/10451/5489/12/ulfc096328_Resumo_Indice.pdf>. Acesso em: 20 de mai. 2018.

OLIVEIRA, S. M. Marketing e sua aplicação em bibliotecas: uma abordagem preliminar. Ciência da Informação, Brasília, v.14, n 2, 1985.

OTTMAN, J. A. Marketing Verde: Desafios e Oportunidades Para a Nova Era do Marketing. São Paulo: Makron Books, 1994.

PEREIRA, K. L. B. A influência do marketing verde no processo de decisão de compra. Unisalesiano, $2011 . \quad$ Disponível em: <http://www.unisalesiano.edu.br/simposio2011/publicado/artigo0030.pdf >. Acesso em: 2 de abril de 2018.

PEREIRA, R.F. et al. Marketing Ambiental: Uma ferramenta empresarial estratégica. Revista Conexão Eletrônica Três Lagoas, v.11,n.1/1,p.871-880,2014.

PORTELA, C. B. M. O Marketing e o Comportamento do Consumidor. 2011. Disponível em: <http://www.convibra.com.br/upload/paper/adm/adm_3488.pdf>. Acesso em: 18 abr. 2018.

PORTO, R. B. Comportamentos relatados de responsabilidade ambiental, social e reciclagem: relação com gênero, idade e estratificação econômica. In: AOS - Amazônia, Organizações e Sustentabilidade, v.1, n.1, jan./jun. 2012, p. 95-107. Disponível em: <http://revistas.unama.br/index.php/aos/article/view/6/11>. Acesso em: 5 dez. 2018.

PRATES, C.C.; CAMPOS, A.S.; SILVA, N.T. A Sustentabilidade no Campo de Gestão e Negócios: um retrato do tema, Porto alegre, 2015. Disponível em: <https://www.lume.ufrgs.br/bitstream/handle/10183/142279/000988462.pdf?sequence=1 $>$.

Acesso em: 22 mar. 2018.

RIBEIRO, E. A. A perspectiva da entrevista na investigação qualitativa. Evidência: olhares e pesquisa em saberes educacionais, Araxá, n. 04, p.129-148, 2008.

SANTOS, D. S.; MENDES D. C. Marketing Verde: Estudo de caso sobre as estratégias de uma organização do segmento de cosméticos. In: XVIII ENANGRADE, 2017, Brasília. Disponível em: <http://www.enangrad.org.br/2017/pdf/2017_ENANGRAD565.pdf>. Acesso em: 21 mar. 2018.

SCHMITZ, C.A. O marketing verde e suas influencias no consumo dos estudantes universitários de Porto Alegre. Porto Alegre, 2014. Disponível em: <https://www.lume.ufrgs.br/bitstream/handle/10183/129855/000944666.pdf?sequence=1>.

Acesso em: 23 mar. 2018.

SOUZA, K. R.; KERBAUY, M. T. M. Abordagem quanti-qualitativa: superação da dicotomia quantitativa-qualitativa na pesquisa em educação. Educação e Filosofia, Uberlândia, v.31, n.61, p.21-44, 2017.

SUSTENTABILIDADE. Resíduos acumulados destinado à reciclagem. Disponível em: <http://www.elizeumartins.com.br/em/>. Acesso em: 29 nov. 2018.

TARIGO, Rodrigo; SILVA, José Edson Azevedo da; GANZER, Paula Patricia; GASPERIN, Daniela; CHAIS, Cassiane; MALAFIA, Guilherme Cunha; OLEA, Pelayo Munhoz. Processo de Decisão de Compra do Consumidor: O Caso de Uma Empresa Varejista. XVI Mostra 
de Iniciação Científica, Pós-graduação, Pesquisa e Extensão. Conferências UCS - Universidade de Caxias do Sul,2016.

TEIXEIRA, M. M.; SILVA, V. B. Comportamento de Compra dos Consumidores em Mercados de Bairros. PMKT - Revista Brasileira de Pesquisas de Marketing, Opinião e Mídia (ISSN 2317-0123 On-line), São Paulo, Brasil, V. 16, p. 62-85, abril, 2015. Disponível em: <http://www.revistapmkt.com.br>. Acesso em: 30 out. 2018.

TELES, C. D. et al. Uma proposta para avaliação da sustentabilidade socioambiental utilizando suporte analítico e gráfico. Production, Santa Catarina, v. 26, n. 2, 417-429, 2016.

TORRES, S.P.; FONSECA, S.C. Marketing de relacionamento: a satisfação e fidelização do cliente. IPTAN - Anuário de produção científica. Ano 1, n.1, 2012.

VEIGA, A. R. N. et. al. Marketing Verde Aplicado à Estratégia como prática: análise de variáveis na visão de empreendedores. Revista Raunp, v.6, n.2, p.23-37, abr./set.2014.

YIN, R. K. Estudo de Caso Planejamento e Métodos. 2. Ed.-Porto Alegre: Bookman, 2001. ZAPPELLINI, M. B.; FEUERSCHÜTTE, S. G. O Uso da Triangulação na Pesquisa Científica Brasileira em Administração. Administração: Ensino e Pesquisa, v.16, n.2, p.241-273, 2015. 